\title{
Platonia insignis Mart., a Brazilian Amazonian Plant: The Stem Barks Extract and Its Main Constituent Lupeol Exert Antileishmanial Effects Involving Macrophages Activation
}

\author{
Adriana Cunha Souza, ${ }^{1}$ Michel Muálem de Moraes Alves, ${ }^{1}$ Lucas Moreira Brito, ${ }^{1}$ \\ Luciano Gomes De Castro Oliveira, ${ }^{1}$ Enoque Pereira Costa Sobrinho-Júnior, ${ }^{1}$ \\ Isabella Cristhina Gonçalves Costa, ${ }^{2}$ Sâmya Danielle Lima Freitas, ${ }^{2}$ \\ Klinger Antonio da Franca Rodrigues, ${ }^{1,3}$ Mariana Helena Chaves, ${ }^{2}$ \\ Daniel Dias Rufino Arcanjo, ${ }^{1}$ and Fernando Aécio de Amorim Carvalho ${ }^{1}$

\footnotetext{
${ }^{1}$ Medicinal Plants Research Center, Federal University of Piauí, SG-15, Ininga, 64049-550 Teresina, PI, Brazil

${ }^{3}$ Department of Biophysics and Pharmacology, Federal University of Rio Grande do Norte, Natal, RN, Brazil
} \\ ${ }^{2}$ Laboratory of Natural Products, Department of Chemistry, Federal University of Piauí, SG-02, Ininga, 64049-550 Teresina, PI, Brazil \\ Correspondence should be addressed to Klinger Antonio da Franca Rodrigues; klinger.antonio@gmail.com
}

Received 4 April 2017; Revised 14 June 2017; Accepted 10 July 2017; Published 9 August 2017

Academic Editor: Victor Kuete

Copyright (C) 2017 Adriana Cunha Souza et al. This is an open access article distributed under the Creative Commons Attribution License, which permits unrestricted use, distribution, and reproduction in any medium, provided the original work is properly cited.

\begin{abstract}
Platonia insignis Mart., popularly known as "bacurizeiro," is used in traditional medical practices based on its diverse biological properties. This study was aimed at evaluating the antileishmanial effects of the ethanol extract (EtOH-Ext), hexane fraction (HexF), and its main isolated Lupeol obtained from stem barks of $P$. insignis against Leishmania (Leishmania) amazonensis, as well as their cytotoxicity and possible mechanisms of action. The EtOH-Ext, Hex-F, and Lupeol inhibited the growth of L. amazonensis promastigote forms at $\mathrm{IC}_{50}$ of $174.24,45.23$, and $39.06 \mu \mathrm{g} / \mathrm{mL}$, respectively, as well as L. amazonensis axenic amastigote forms at $\mathrm{IC}_{50}$ of $40.58,35.87$, and $44.10 \mu \mathrm{g} / \mathrm{mL}$, respectively. The mean cytotoxic concentrations for macrophages $\left(\mathrm{CC}_{50}\right)$ were higher than those for amastigotes $(341.95,71.65$, and $144.0 \mu \mathrm{g} / \mathrm{mL}$, resp.), indicating a selective cytotoxicity towards the parasite rather than the macrophages. Interestingly, all treatments promoted antileishmanial effect against macrophage-internalized amastigotes at concentrations lower than $\mathrm{CC}_{50}$. Furthermore, increases of lysosomal volume of macrophages treated with EtOH-Ext, Hex-F, and Lupeol were observed. On the other hand, only Lupeol stimulated increase of phagocytic capability of macrophages, suggesting this compound might be characterized as the biomarker for the antileishmanial effect of $P$. insignis stem bark, as well as the involvement of immunomodulatory mechanisms in this effect.
\end{abstract}

\section{Introduction}

Leishmaniasis are parasitic diseases caused by protozoa from Leishmania genus. Humans are infected by the sting of sand flies which live in forest areas, caves, or rodent dens. This pathology is widely distributed throughout the world and occurs in Asia, Europe, Africa, and the Americas. Furthermore, there have been some reports of its occurrence in the American continent since colonial times [1,2]. Leishmaniasis is capable of affecting both man and animals, affecting more than 12 million people worldwide, with 2 to 3 million of new cases each year $[2,3]$. According to the World Health Organization (WHO), approximately 556 million people were in areas at risk of contamination of visceral leishmaniasis and 399 million for cutaneous leishmaniasis in 2014 [2].

Since the 1940s, chemotherapy of leishmaniasis has been based on the use of pentavalent antimonials as first choice drugs, such as sodium stibogluconate (Pentostan ${ }^{\circledR}$ ) and meglumine antimoniate (Glucantime ${ }^{\circledR}$ ) [4]. Second-line drugs, such as pentamidine and amphotericin B, are important 
in the therapy of patients with coinfections, or in cases of resistance to antimonials $[5,6]$. However, these drugs require long-term parenteral administration and have serious adverse effects in addition to high relapse rates, especially in immunocompromised patients [5, 7]. Therefore, considering these difficulties, the search for new safer and more effective chemotherapeutic agents is markedly relevant.

The use of medicinal plants is a very promising alternative. Plants biosynthesize compounds for their own defense in response to an environmental attack [8]. Its importance is evidenced by the wide diversity of metabolites produced by these species, with distinct chemical, physical, and biological characteristics, most of them possibly bioactive against Leishmania sp. [9]. In this context, substances obtained from native species from Brazil which present antileishmanial activity and low toxicity may represent alternatives for the conventional treatment of leishmaniasis.

Platonia insignis Mart., popularly known as "bacurizeiro," is a fruit and woody plant with dense and diversified population, occurring from the Amazon to Piauí in Brazil. It belongs to the Clusiaceae family, composed of 1000 species and 47 genera, distributed in tropical, subtropical, and temperate regions [10]. In Brazil, the use of $P$. insignis in traditional medical practices is based on its diverse biological properties, such as cicatrizant, antimicrobial, digestive, diuretic, antitumor, cytotoxic, and antioxidant [11].

Studies on the antileishmanial activity of medicinal plants represent a great challenge for the discovery and identification of new bioactive substances. Moreover, there are no studies regarding the antileishmanial potential of the extracts and fractions obtained from the stem bark of $P$. insignis. Therefore, this work aimed to assess the potential antileishmanial activity, cytotoxicity, and immunomodulatory effect of ethanol extract (EtOH-Ext), its hexanic fraction (Hex-F), and the main constituent Lupeol obtained from the stem bark of $P$. insignis.

\section{Material and Methods}

2.1. Chemicals. Dimethyl sulfoxide (DMSO: 99\%), anhydrous sodium sulfate, glacial acetic acid, ethanol, formaldehyde, sodium chloride, calcium acetate, zymosan, and neutral red were purchased from Merck Chemical Company (Germany). Schneider's medium, RPMI 1640 medium, fetal bovine serum (FBS), MTT (3-(4,5-dimethylthiazol-2-yl)2,5diphenyltetrazolium bromide), Griess reagent (1\% sulfanilamide in $\mathrm{H}_{3} \mathrm{PO}_{4} 10 \%(\mathrm{v} / \mathrm{v})$ in Milli-Q water), and the antibiotics penicillin and streptomycin were purchased from Sigma Chemical (St. Louis, MO, USA). The antibiotic amphotericin B $(90 \%)$ was purchased from Cristália (São Paulo, SP, Brazil).

2.2. Plant Material. The stem bark of $P$. insignis was collected in September 2010, from the municipality of Timon, Maranhão, Brazil. The voucher specimen is deposited in the Herbarium Graziela Barroso of the Federal University of Piauí, Brazil, under number TEPB 20701.

2.3. Extraction of EtOH-Ext and Hex-F from Stem Bark of $P$. insignis. The stem bark of $P$. insignis was dried at room temperature and then powdered. The material obtained $(1.1 \mathrm{~kg})$ was exhaustively extracted six consecutive times with ethanol, during five days each using the following extraction procedure. Following removal of the solvent at low pressure in the rotary evaporator and lyophilization, the EtOH-Ext $(114.5 \mathrm{~g})$ was obtained. Afterwards, the EtOH-Ext extract (90.0 g) was suspended in a $\mathrm{MeOH} / \mathrm{H}_{2} \mathrm{O}$ mixture $(2: 3)$, and subjected to the liquid-liquid partitioning process with hexane, resulting in the Hex-F (9.8 g; yield of 10.9\%).

The EtOH-Ext and Hex-F were solubilized in DMSO to obtain stock solutions at $80 \mathrm{mg} / \mathrm{mL}$. In each protocol, the stock solution was diluted in the appropriate culture media to reach the desired concentration, not exceeding the concentration of $0.5 \%$ DMSO.

2.4. Isolation of Triterpene Lupeol from Hex-F. The Hex-F (7.2 g) was subjected to column chromatography of silica gel $(210 \mathrm{~g})$, using hexane and ethyl acetate as eluent solvents. Fifty fractions were obtained. Similar fractions were then merged according to thin layer chromatography analysis. The group HB34 (fractions 34 to $36,1370 \mathrm{mg}$, yield of 19.6\%) was obtained after elution with hexane : AcOEt $(95: 5)$, and then analyzed by ${ }^{1} \mathrm{H}$ NMR and ${ }^{13} \mathrm{C}$. The compound 1 was identified as follows:

Lupeol (1). White amorphous solid. RMN ${ }^{1} \mathrm{H}(400 \mathrm{MHz}$, $\mathrm{CDCl}_{3}$ ): $\delta 1,67$ (s, H-30), 3,18 (dd, $\left.J=11.1,5.1 \mathrm{~Hz}, \mathrm{H}-3\right), 4,56$ $(J=2.4 \mathrm{~Hz}, \mathrm{H}-29 \mathrm{a}), 4,68(J=2.4 \mathrm{~Hz}, \mathrm{H}-29 \mathrm{~b}) . \mathrm{RMN}{ }^{13} \mathrm{C}$ $\left(100 \mathrm{MHz}, \mathrm{CDCl}_{3}\right): \delta 38.8(\mathrm{C}-1), 27.6(\mathrm{C}-2), 79.1$ (C-3), 39.0 (C-4), 55.4 (C-5), 18.4 (C-6), 34.4 (C-7), 41.0 (C-8), 50.6 (C9), 37.3 (C-10), 21.1 (C-11), 25.3 (C-12), 38.2 (C-13), 42.9 (C-14), 27.5 (C-15), 35.7 (C-16), 43.1 (C-17), 48.4 (C-18), 48.1 (C-19), 151.0 (C-20), 30.0 (C-21), 40.1 (C-22), 28.1 (C-23), 15.5 (C-24), 16.2 (C-25), 16.1 (C-26), 14.7 (C-27), 18.1 (C-28), 109.5 (C-29), 19.4 (C-30).

2.5. Leishmania Culture Conditions. Leishmania (Leishmania) amazonensis (IFLA/BR/67/PH8) was maintained as amastigote forms by several weekly passages in BALB/c mice, and as promastigote forms at $26^{\circ} \mathrm{C}$ in supplemented Schneider's medium, pH 7.0 (10\% heat-inactivated fetal bovine serum (FBS), $100 \mathrm{U} / \mathrm{mL}$ penicillin, and $100 \mu \mathrm{g} / \mathrm{mL}$ streptomycin), as previously described [12]. Extracellular amastigote-like forms were obtained by in vitro differentiation of promastigotes of Leishmania amazonensis in the stationary growth phase by increasing the temperature to $32^{\circ} \mathrm{C}$ and decreasing the $\mathrm{pH}$ to 4.6 [13].

2.6. Animals and Murine Peritoneal Macrophages. Male and female BALB/c mice (4-5 weeks old) obtained from Section of Biotherium from Medicinal Plants Research Center of Federal University of Piauí, (Teresina, Piauí, Brazil), were maintained under controlled temperature $\left(24 \pm 1^{\circ} \mathrm{C}\right)$ and light conditions (12-h light/dark cycle). Inflammatory peritoneal macrophages were collected 5 days after intraperitoneal administration with $1.5 \mathrm{~mL}$ of $3 \%$ thioglycollate medium. Animals were handled according to the Resolution number 1000/2012 (Federal Council of Veterinary Medicine, Brazil) for the Care and Use of Animals. All experimental protocols 
were approved by the Research Ethics Committee (CEEAUFPI number 014/2015).

2.7. Bioassay of Promastigote and Axenic Amastigote Forms of Leishmania amazonensis. Promastigote and axenic amastigote forms were seeded in 96-well plates containing Schneider's supplemented medium $\left(1 \times 10^{6}\right.$ Leishmania per $100 \mu \mathrm{l}$ medium). Then, EtOH-Ext, Hex-F, and Lupeol were added in triplicate at the concentrations of $6.25,12.5,25,50,100,200$, 400 , and $800 \mu \mathrm{g} / \mathrm{mL}$. Amphotericin B (Amph B, $2 \mu \mathrm{g} / \mathrm{mL}$ ) was used as positive control. The plate was maintained in a biological oxygen demand (BOD) incubator at a temperature of $26^{\circ} \mathrm{C}$ for $48 \mathrm{~h}$. Six hours before the end of this period, resazurin $\left(1 \times 10^{-3} \mathrm{~mol} / \mathrm{L}, 20 \mu \mathrm{L}\right)$ was added in each well. All the absorbance was read using a Biotek microplate reader (model ELx800) at $550 \mathrm{~nm}$. The results were expressed as percent inhibition in growth [14].

2.8. Investigation of EtOH-Ext, Hex-F, and Lupeol Activities on L. amazonensis-Infected Macrophages. Murine peritoneal macrophages were harvested and plated on a 24-well microplate $\left(1 \times 10^{6}\right.$ cells $\left./ \mathrm{mL}\right)$ in supplemented RPMI 1640 $(10 \%$ inactivated FBS, $100 \mathrm{U} / \mathrm{ml}$ penicillin, and $100 \mu \mathrm{g} / \mathrm{mL}$ streptomycin), containing sterile $13 \mathrm{~mm}$ round coverslips. Culture plates were incubated at $37^{\circ} \mathrm{C}$ and $5 \% \mathrm{CO}_{2}$ for $3 \mathrm{~h}$ for cell adhesion. Adhered macrophages were then incubated with a new medium containing promastigotes (in stationary phase) at a ratio of ten promastigotes to one macrophage at $5 \% \mathrm{CO}_{2}$ and $37^{\circ} \mathrm{C}$ for $4 \mathrm{~h}$. Afterwards, the cells were washed with $0.01 \mathrm{M}$ phosphate buffered saline (PBS). Then, the EtOH-Ext, Hex-F, and Lupeol were incubated for $48 \mathrm{~h}$ at concentrations related to the $\mathrm{IC}_{50}, 1 / 2 \mathrm{IC}_{50}$, and $1 / 4 \mathrm{IC}_{50}$ of each treatment against promastigote forms, as well as Amph B $(2 \mu \mathrm{g} / \mathrm{mL})$ as positive control. After this period, the coverslips were removed and stained with Panoptic staining kit. For each treatment, the number of infected macrophages and the parasite load were counted using optical microscopy [12].

2.9. Cytotoxic Effect on Macrophages and Determination of Selectivity Index (SI). Cytotoxicity evaluation was carried out in 96-well plates using the MTT assay. Approximately $1 \times$ $10^{6}$ murine peritoneal macrophages per well were incubated in $100 \mu \mathrm{L}$ of supplemented RPMI 1640 medium at $37^{\circ} \mathrm{C}$ and $5 \% \mathrm{CO}_{2}$ for $4 \mathrm{~h}$ for cell adhesion. Nonadherent cells were removed by washing with RPMI 1640 medium. Then, EtOHExt, Hex-F, and Lupeol were diluted in supplemented RPMI 1640 medium, added at concentrations of $6.25,12.5,25,50$, $100,200,400$, and $800 \mu \mathrm{g} / \mathrm{mL}$, and incubated at $37^{\circ} \mathrm{C}$ with $5 \% \mathrm{CO}_{2}$ for two days. Following incubation, cytotoxicity was assessed by adding MTT $(5 \mathrm{mg} / \mathrm{mL})$. The supernatant was discarded and the formazan crystals were dissolved in $100 \mu \mathrm{L}$ of DMSO. Finally, absorbance was measured at $550 \mathrm{~nm}$ using Biotek microplate reader (model ELx800). Selectivity index of each treatment was calculated at the ratio of mean cytotoxicity concentration $\left(\mathrm{CC}_{50}\right)$ for $\mathrm{BALB} / \mathrm{c}$ mice murine peritoneal macrophages and half-maximal inhibitory concentration $\left(\mathrm{CI}_{50}\right)$ for macrophage-internalized amastigote forms of L. amazonensis [15].

\subsection{Evaluation of Immunomodulatory Activity}

2.10.1. Solutions. The stock solution of neutral red (NR) dye was prepared by solubilizing $0.002 \mathrm{~g}$ in $1 \mathrm{~mL}$ of DMSO. The extraction solution used in protocols described in Sections 2.10 .2 and 2.10 .3 consisted of $96 \%$ glacial acetic acid $(1.0 \%)$ and ethanol (50\%) dissolved in deionized water (v/v). The staining of macrophages for the phagocytic capability assay was obtained by diluting $0.3 \mathrm{~mL}$ of the neutral red solution and $0.02 \mathrm{~g}$ of zymosan in $3 \mathrm{~mL}$ of PBS. The Baker's fixative solution was composed of $4 \%$ formaldehyde ( $/ / \mathrm{v}), 2 \%$ sodium chloride $(\mathrm{w} / \mathrm{v})$, and $1 \%$ calcium acetate $(\mathrm{w} / \mathrm{v})$ in deionized water. Griess' reagent was prepared with $1.0 \%$ sulfanilamide in $10 \% \mathrm{H}_{3} \mathrm{PO}_{4}(\mathrm{v} / \mathrm{v})$ and $0.1 \%$ naphtylenediamine in Milli- ${ }^{\circledR}$ water.

2.10.2. Lysosomal Volume. The uptake of the cationic dye NR from lysosomal compartments of macrophages was assessed as previously described [16]. Murine peritoneal macrophages $\left(1 \times 10^{6}\right.$ cells per well) were harvested and plated with $\mathrm{EtOH}-$ Ext, Hex-F, and Lupeol in serial dilutions at $37^{\circ} \mathrm{C}$ and $5 \% \mathrm{CO}_{2}$ for $48 \mathrm{~h}$. Next, cells were treated with $10 \mu \mathrm{L}$ of $2 \%$ neutral red solution (see Section 2.10.1) and incubated for $30 \mathrm{~min}$. The wells were subsequently washed twice with PBS, and the internalized neutral red was solubilized by adding the extraction solution (see Section 2.10.1). After $30 \mathrm{~min}$ on a Kline shaker (model AK 0506), the absorbance at $550 \mathrm{~nm}$ was measured as above.

2.10.3. Phagocytosis Capability. Murine peritoneal macrophages $\left(1 \times 10^{6}\right.$ cells per well $)$ were harvested and plated with EtOH-Ext, Hex-F, and Lupeol in serial dilutions at $37^{\circ} \mathrm{C}$ and $5 \% \mathrm{CO}_{2}$ for $48 \mathrm{~h}$. After incubation, $10 \mu \mathrm{L}$ of NR-stained zymosan solution (described above) was added and the cells were incubated at $37^{\circ} \mathrm{C}$ for $30 \mathrm{~min}$. Following incubation, $100 \mu \mathrm{L}$ of Baker's fixative solution (see Section 2.10.1) was added in order to stop the phagocytosis of zymosan. After $30 \mathrm{~min}$, the cells were washed with PBS to remove nonphagocytosed NR and zymosan. Then, NR was solubilized by adding the extraction solution (see Section 2.10.1) in the Kline shaker. The absorbance was subsequently measured at $550 \mathrm{~nm}$ as above [17].

2.10.4. Nitrite Measurement. Murine peritoneal macrophages $\left(2 \times 10^{5}\right.$ cells per well $)$ were harvested and plated with EtOHExt, Hex-F, and Lupeol in serial dilutions at $37^{\circ} \mathrm{C}$ and $5 \%$ $\mathrm{CO}_{2}$ for $24 \mathrm{~h}$. Then, the supernatants $(100 \mu \mathrm{L})$ were incubated with equal parts of Griess' reagent (see Section 2.10.1), and the absorbance was read at $550 \mathrm{~nm}$ as above. The standard curve was prepared with sodium nitrite in Milli-Q water at concentrations of $1,5,10,25,50,75,100$, and $150 \mu \mathrm{M}$ diluted in RPMI 1640 medium [18].

2.11. Statistical Analysis. All assays were performed in triplicate in three independent experiments. The mean inhibitory concentration $\left(\mathrm{IC}_{50}\right)$ and mean cytotoxic concentration $\left(\mathrm{CC}_{50}\right)$ were calculated using probit regression with $95 \%$ confidence limit using SPSS software version 13.0. Oneway analyses of variance (ANOVA) followed by Bonferroni's 


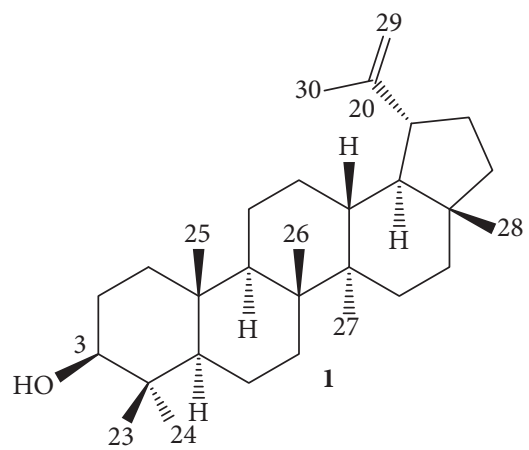

FIgURE 1: The triterpene Lupeol.

post hoc test were performed using the GraphPad Prism software version 5.0. Differences were considered statistically significant when $P<0.05$.

\section{Results}

3.1. Identification of Lupeol in Hex-F. The hexane fraction from $P$. insignis (Hex-F) provides Lupeol as the major compound (Figure 1), confirmed by comparison between ${ }^{1} \mathrm{H}$ NMR spectra of the Hex-F and the isolated compound (Figure 2). The Lupeol was identified after isolation and analysis by ${ }^{1} \mathrm{H}$ and ${ }^{13} \mathrm{C}$ NMR when compared with data previously reported [19].

3.2. Anti-Leishmania Activity Assay. The EtOH-Ext promoted statistically significant inhibition of L. amazonensis promastigotes forms at all concentrations tested (Figure 3(a)). Besides, the Hex-F showed growth inhibition ranging from the concentration of $12.5 \mu \mathrm{g} / \mathrm{mL}$ to $400 \mu \mathrm{g} / \mathrm{mL}$, where $100 \%$ of inhibition was achieved (Figure 3(b)). Lupeol was the most effective in promoting growth inhibition of promastigotes, with significant inhibition at all concentrations tested (Figure 3(c)). The mean inhibitory concentrations for EtOHExt, Hex-F, and Lupeol against promastigote forms were calculated and listed in Table 1.

In another set of experiments, the effects of EtOH-Ext, Hex-F, and Lupeol on axenic amastigote forms of L. amazonensis were assessed. The EtOH-Ext exhibited a significant inhibitory effect starting from the lowest concentration tested (Figure 4(a)), whereas the inhibitory effect of Hex-F started at concentration of $12.5 \mu \mathrm{g} / \mathrm{mL}$, reaching $100 \%$ of inhibition at the highest concentration tested (Figure 4(b)). The Lupeol presented significant anti-Leishmania activity when compared to control started at concentration of $25 \mu \mathrm{g} / \mathrm{mL}$ (Figure $4(\mathrm{c})$ ). The mean inhibitory concentrations $\left(\mathrm{IC}_{50}\right)$ for EtOH-Ext, Hex-F, and Lupeol against axenic amastigote forms were calculated and listed in Table 1.

3.3. Cytotoxicity Determination. The EtOH-Ext demonstrated significant cytotoxicity starting from the concentration of $25 \mu \mathrm{g} / \mathrm{mL}$, presenting higher cytotoxic effect at concentrations of 400 and $800 \mu \mathrm{g} / \mathrm{mL}$ (Figure 5(a)). Thereafter, the Selectivity index (SI) was calculated by the ratio of mean cytotoxic concentration $\left(\mathrm{CC}_{50}\right)$ and mean inhibitory concentration $\left(\mathrm{IC}_{50}\right)$ for axenic amastigote forms of $L$. amazonensis. The EtOH-Ext presented a selectivity index of 8.42, indicating the EtOH-Ext is around 8-fold more cytotoxic to the parasite than to the host cells.

The Hex-F showed significant cytotoxicity (Figure 5(b)) by altering the viability of the cells starting from the concentration of $50 \mu \mathrm{g} / \mathrm{mL}$, with the maximal cytotoxic effect at $200 \mu \mathrm{g} / \mathrm{mL}$, and SI of 1.99 (Table 1). On the other hand, the main constituent Lupeol also significantly affected the viability of macrophages (Figure 5(c)), with $\mathrm{CC}_{50}$ and SI higher than those obtained for Hex-F. These results indicate less cytotoxicity to the host cells with similar efficacy against the parasite (Table 1).

3.4. Effect on Macrophage Infection. The effects of the treatment with EtOH-Ext, Hex-F, and Lupeol of macrophages infected with L. amazonensis are shown in Figure 6. They were able to significantly reduce the number of infected macrophages in all tested concentrations when compared to the control (Figure 6(a)). Furthermore, a significant decrease of number of internalized amastigotes was observed in all tested concentrations of EtOH-Ext, Hex-F, and Lupeol when compared with control group (Figure 6(b)).

3.5. Lysosomal Volume and Phagocytosis Test. The lysosomal volume was assessed by the retention of the NR the lysosome of macrophages and then determined colorimetrically. The EtOH-Ext induced a significant increase of lysosomal volume of macrophages at concentrations of $6.25,12.5$, and $25 \mu \mathrm{g} / \mathrm{mL}$ (Figure $7(\mathrm{a})$ ). Besides, the lysosomal volume after treatment with Hex-F increased significantly at concentrations of 6.25 and $12 \mu \mathrm{g} / \mathrm{mL}$ (Figure 7(b)). Interestingly, the lysosomal volume of macrophages treated with Lupeol showed a statistically significant increase of the endocytic volume at concentrations ranging from 6.25 to $50 \mu \mathrm{g} / \mathrm{mL}$ of Lupeol (Figure 7(c)).

Other parameter related to macrophages activation parameter was the phagocytic capability of stained zymosan particles. Both EtOH-Ext and Hex-F were not able to promote any increase in the phagocytic capability of macrophages (Figures 8(a) and 8(b)). Interestingly, a significant increase in phagocytosis of zymosan particles was observed in 


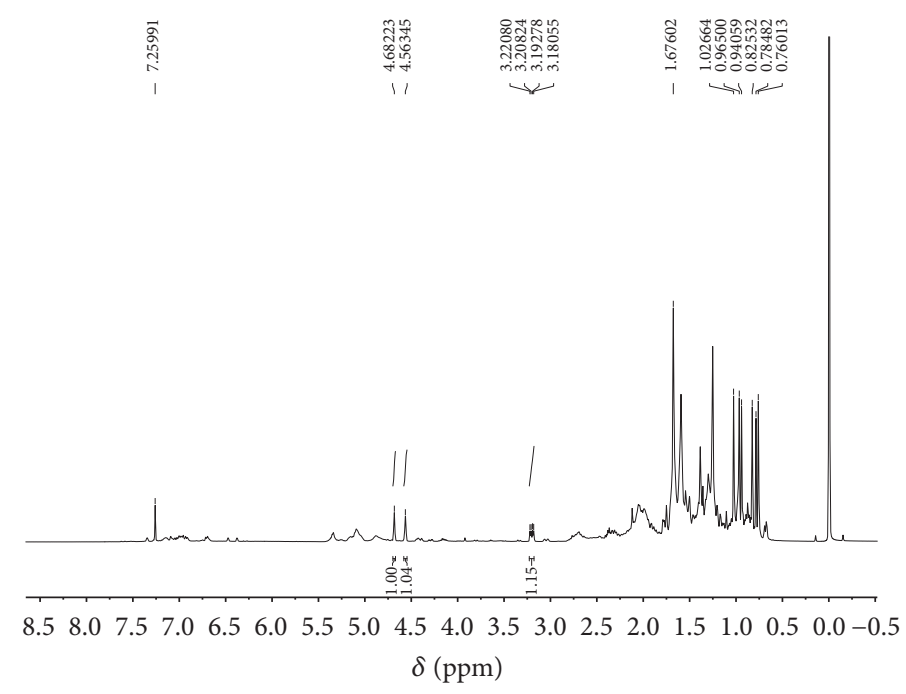

(a)

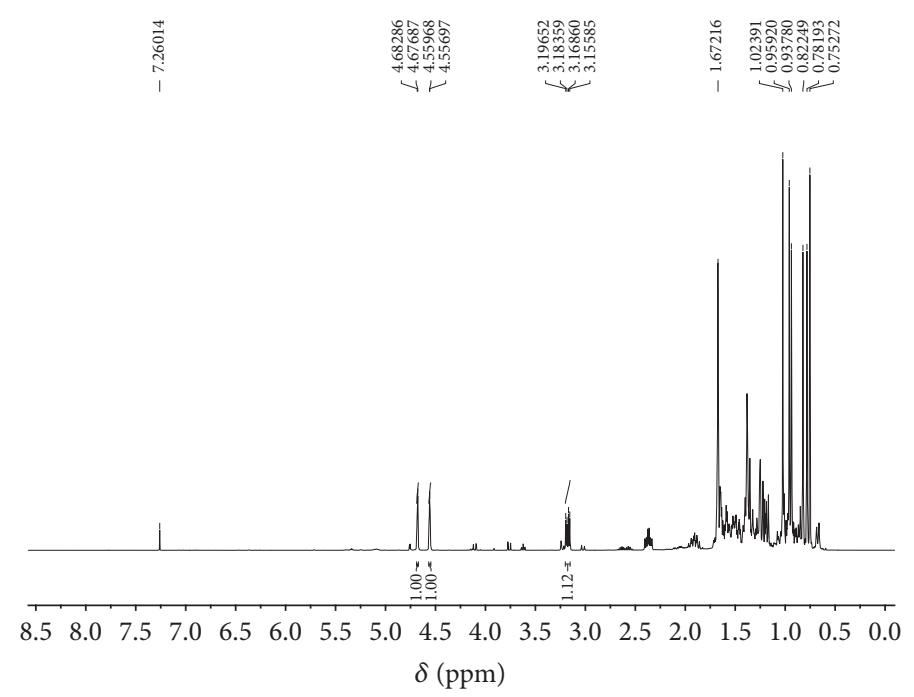

(b)

Figure 2: ${ }^{1} \mathrm{H}$ NMR spectra $\left(\mathrm{CDCl}_{3}, 400 \mathrm{MHz}\right)$ : Hex-F (a) and Lupeol (b).

macrophages treated with Lupeol at concentrations ranging from 6.25 to $25.0 \mu \mathrm{g} / \mathrm{mL}$ (Figure $8(\mathrm{c})$ ).

3.6. Measurement of Nitrite Production. The nitrite measurement was determined in macrophages after incubation with EtOH-Ext, Hex-F, and Lupeol. No increase in nitrite production was observed after all treatments. Furthermore, a decrease in nitrite production was observed only at concentrations higher than those observed for lysosomal volume and phagocytic capability (Figure 9).

\section{Discussion}

Scientific studies related to the pharmacological potential of medicinal plants have been increasing. The use of medicinal plants in traditional medical practices has increasingly proved that stems, roots, leaves, seeds, and fruits of these plants have appreciable efficacy in the cure of several diseases. Previous studies have demonstrated potent antileishmanial activity of extracts and fractions from leaves and fruit peels of Azadirachta indica with $\mathrm{IC}_{50}$ value of $1.1 \mu \mathrm{g} / \mathrm{mL}$ against promastigote forms, and $0.4 \mu \mathrm{g} / \mathrm{mL}$ against amastigote forms, as well as low cytotoxicity against mammalian cells [12]. Furthermore, the essential oil from leaves of Eugenia uniflora demonstrated a marked antileishmanial effect with $\mathrm{IC}_{50}$ of $1.75 \mu \mathrm{g} / \mathrm{mL}$ against promastigotes, and $1.92 \mu \mathrm{g} / \mathrm{mL}$ against amastigotes [15]. Thus, the observation of the therapeutic properties of natural products has led towards the research of the active principles from several plant species $[15,20]$.

The $P$. insignis species, called "bacuri" provides a very popular consumed fruit among the Brazilian Amazonian people. This ethnopharmacological use is related to the 


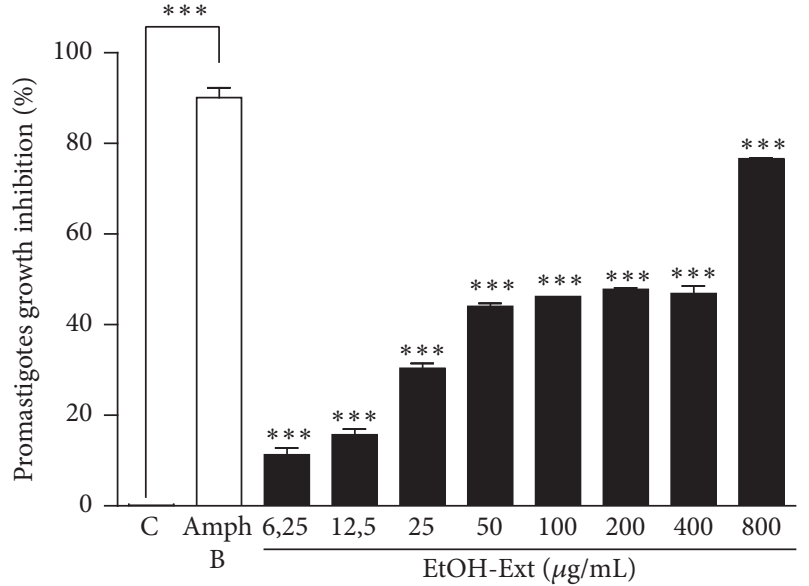

(a)

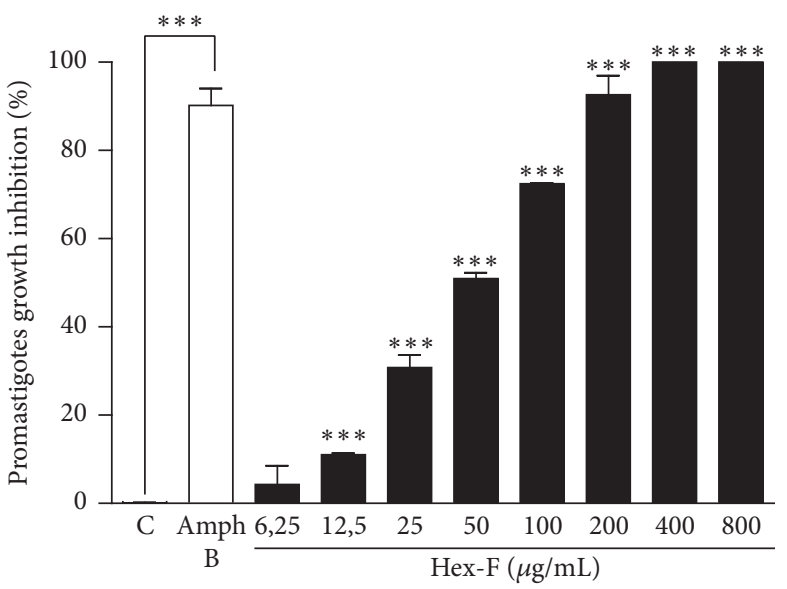

(b)

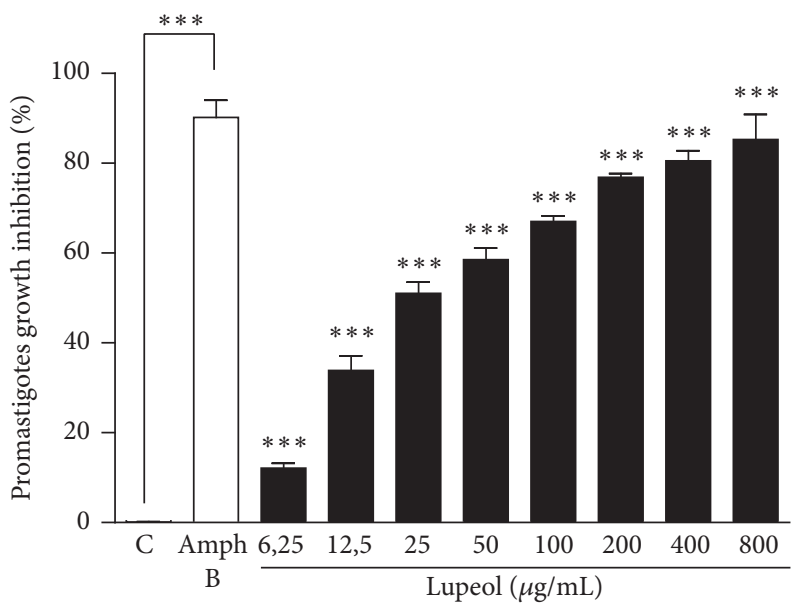

(c)

Figure 3: Anti-Leishmania activity of EtOH-Ext (a), Hex-F (b), and Lupeol (c) from P. insignis stem bark against promastigote forms of $L$. amazonensis. Parasites $\left(1 \times 10^{6}\right)$ were exposed to different concentrations for $48 \mathrm{~h}$, and cell viability was assessed by resazurin assay. ${ }^{* * *} P<$ 0.001 versus control.

TABLE 1: Anti-Leishmania activity of EtOH-Ext, Hex-F, and Lupeol from P. insignis stem bark, and cytotoxic effects against murine peritoneal macrophages.

\begin{tabular}{|c|c|c|c|c|}
\hline \multirow{2}{*}{ Compounds } & \multirow{2}{*}{$\begin{array}{l}\text { Macrophages } \\
\mathrm{CC}_{50}(\mu \mathrm{g} / \mathrm{mL})\end{array}$} & \multirow{2}{*}{$\begin{array}{l}\text { Promastigotes } \\
\mathrm{CI}_{50}(\mu \mathrm{g} / \mathrm{mL})\end{array}$} & \multicolumn{2}{|c|}{ Axenic amastigotes } \\
\hline & & & $\mathrm{CI}_{50}(\mu \mathrm{g} / \mathrm{mL})$ & SI \\
\hline EtOH-Ext & 341.95 & 174.24 & 40.58 & 8.42 \\
\hline Hex-F & 71.65 & 45.23 & 35.87 & 1.99 \\
\hline Lupeol & 144.00 & 39.06 & 44.10 & 3.26 \\
\hline Amph B & 8.75 & 1.74 & 0.20 & 43.75 \\
\hline
\end{tabular}

SI: Selectivity index for axenic amastigote forms of L. amazonensis $\left(\mathrm{CC}_{50} / \mathrm{IC}_{50}\right)$.

seeds extract as cicatrizant and anti-inflammatory agents. Currently, several activities have been reported for all parts of this fruit (seed, shells, and pulp). Besides, classes of terpenes, xanthones, and phenolics have been reported as major constituents [21]. The Hex-F obtained from the stem bark of $P$. insignis presents the triterpene Lupeol as its major constituent. Triterpenes have aroused a marked interest due to their broad spectrum of biological activities [22]. In this context, the triterpene Lupeol has demonstrated potential application in studies concerning the discovery of compounds with antitumor and anti-inflammatory activities [23]. 


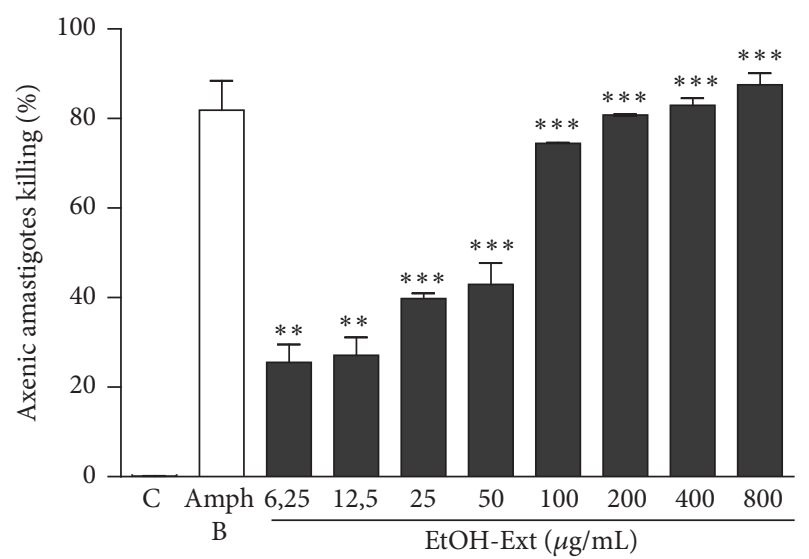

(a)

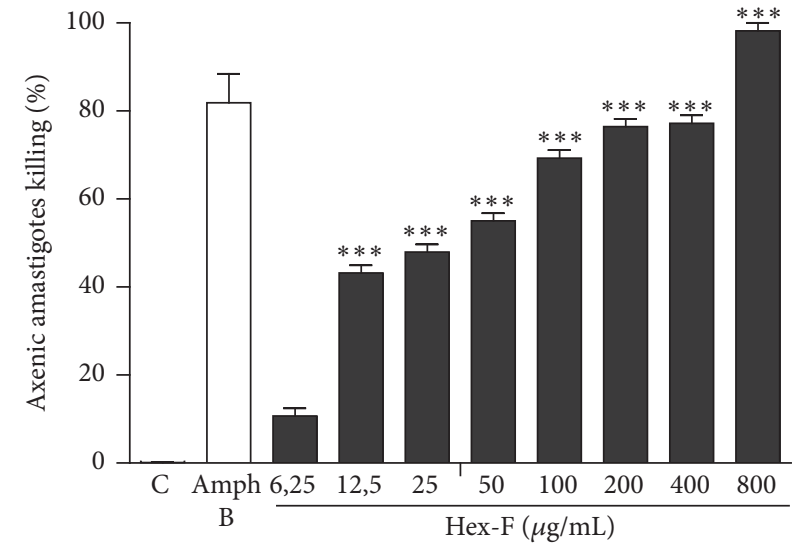

(b)

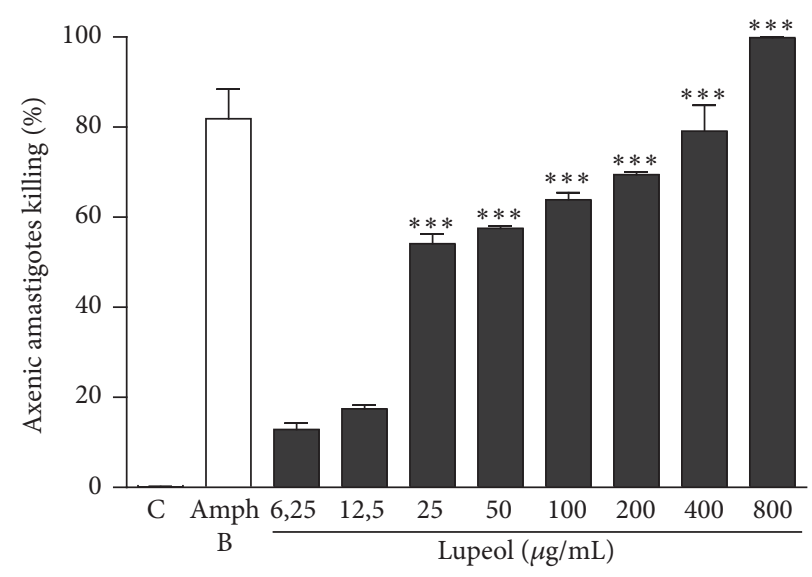

(c)

Figure 4: Anti-Leishmania activity of EtOH-Ext (a), Hex-F (b), and Lupeol (c) against axenic amastigote forms of L. amazonensis. Parasites $\left(1 \times 10^{6}\right)$ were exposed to different concentrations for $48 \mathrm{~h}$, and cell viability was assessed by resazurin assay. ${ }^{* *} P<0.01$ versus control; ${ }^{* * *} P<0.001$ versus control.

The screening of leishmanicidal agents classically uses promastigotes forms due to their simplicity and low cost of the culture [24]. Moreover, Costa-Júnior and colaborators [25] have reported the antileishmanial effect of garcinielliptone FC, a polyisoprenilated benzophenone isolated from the seed extracts of $P$. insignis, with a $\mathrm{IC}_{50}$ value of $25.78 \mu \mathrm{g} / \mathrm{mL}$. This evidence reinforces the anti-Leishmania potential of these plant species. In this context, EtOH-Ext, Hex-F, and Lupeol demonstrated in vitro efficacy against both promastigotes and axenic amastigotes of L. amazonensis. In this study, no significant difference was observed between $\mathrm{IC}_{50}$ values obtained for Lupeol and Hex-F, then indicating the Hex-Finduced antileishmanial effect might be related to its Lupeol content. Thus, the triterpene Lupeol can be characterized as a biomarker for the antileishmanial activity of $P$. insignis.

Previous studies have suggested that lipophilic compounds, such as triterpenes, act by a peculiar mechanism. These compounds can pass easily through the cytoplasmic membranes, affecting structures of their different layers of polysaccharides, fatty acids, and phospholipids, thus making them permeable [26]. Once they cross the membrane, the coagulation of cytoplasm can occur. These events are able to promote the interruption of specific metabolic pathways of lipids and proteins [27], interference in cell division [28, 29], or stimulate the depolarization of the mitochondrial membranes, which can lead the cell to trigger necrosis or apoptosis mechanisms [30].

Considering that EtOH-Ext, Hex-F, and Lupeol showed significant antileishmanial activity, the investigation of the cytotoxic activity against mammalian cells as potential hosts is markedly necessary. Cytotoxicity tests against murine peritoneal macrophages were performed by the resazurin colorimetric assay [31]. In these experiments, $\mathrm{CC}_{50}$ values higher than the $\mathrm{IC}_{50}$ values for promastigotes and axenic amastigotes were found. Conversely, previous studies have found a SI lower than 1.0 for meglumine antimoniate, the reference drug for treatment of leishmaniasis, demonstrating a higher cytotoxicity against macrophages than the parasite. This result is related to the in vivo effects of pentavalent antimonials, where, despite being first-line drugs for the treatment of cutaneous and visceral leishmaniasis, numerous side effects and toxicity have been reported [32]. Therefore, 


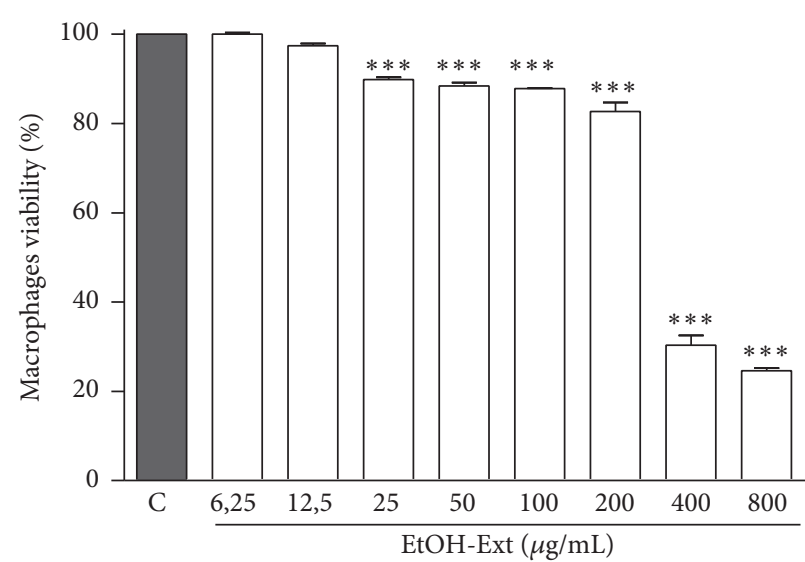

(a)

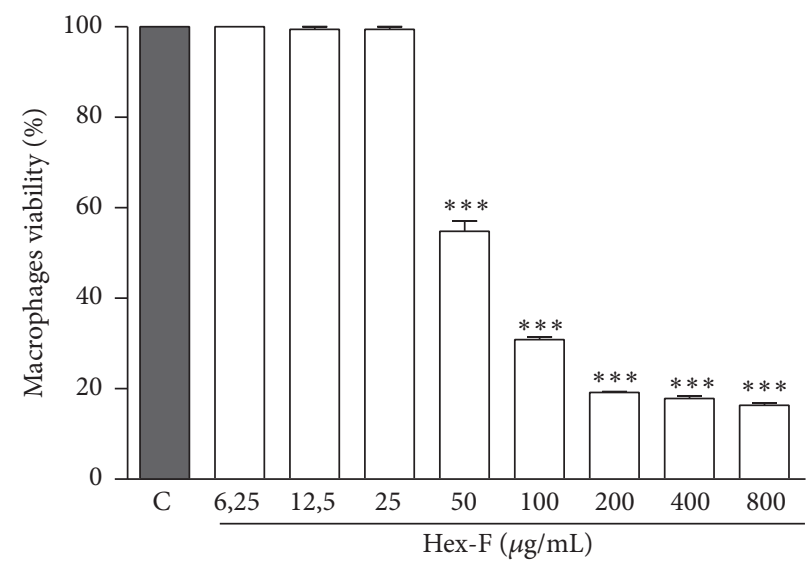

(b)

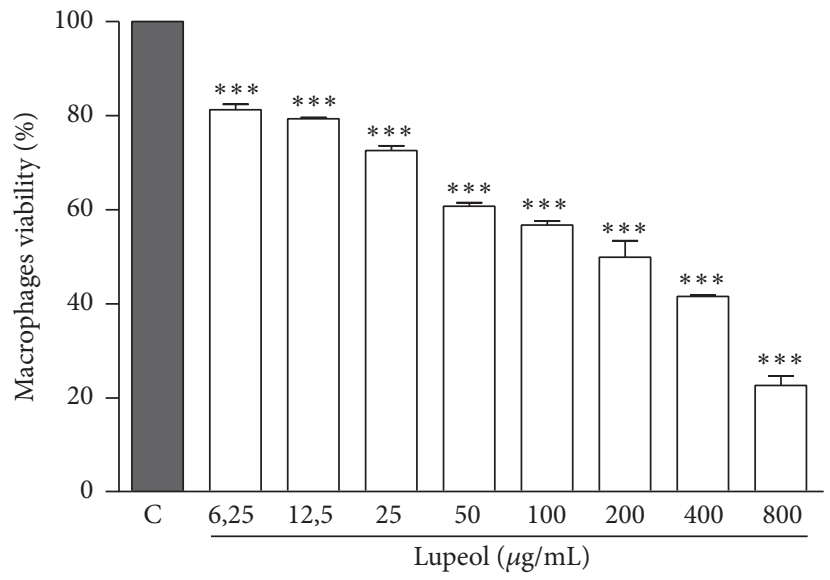

(c)

Figure 5: Cytotoxic effects against murine peritoneal macrophages of EtOH- Ext (a), Hex-F (b), and Lupeol (c). Murine peritoneal macrophages were incubated for $48 \mathrm{~h}$ in the presence of different concentrations. Macrophage viability was measured by MTT assay (MTT). Data are expressed as means \pm SEM of three experiments performed in triplicate. ${ }^{* * *} P<0.001$ versus control.

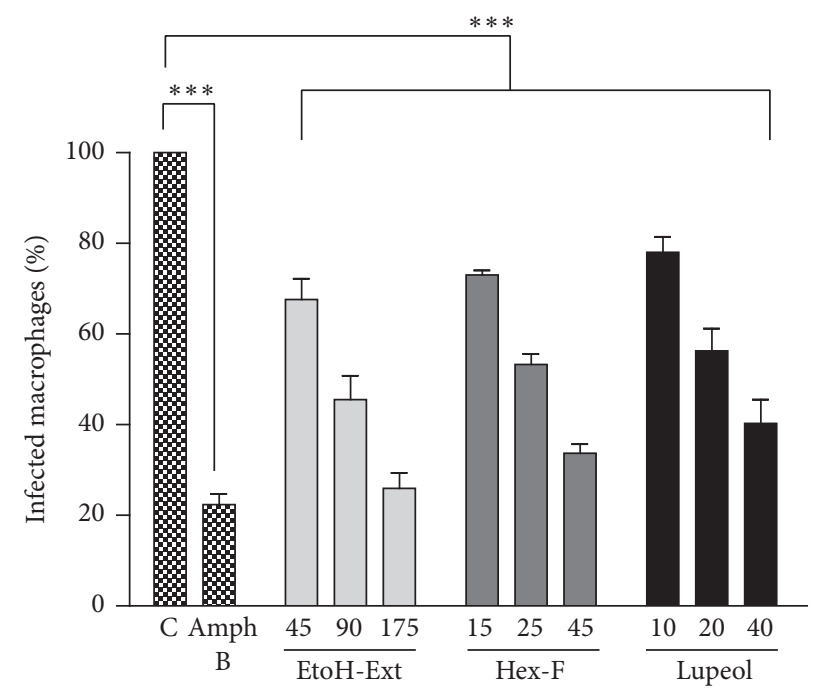

(a)

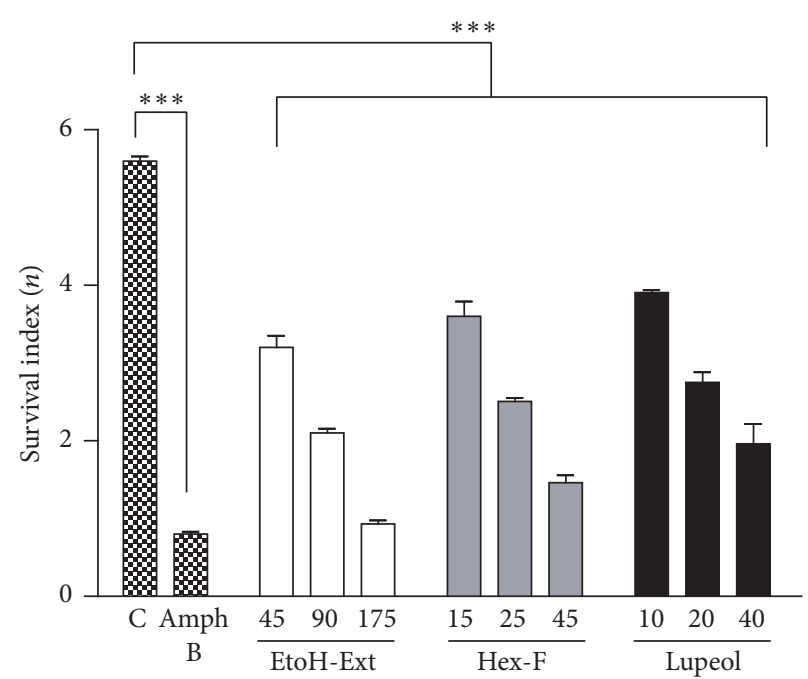

(b)

Figure 6: Effect of EtOH-Ext, Hex-F, Lupeol, and the reference drug Amph B ( $2 \mu \mathrm{g} / \mathrm{mL})$ on the infected macrophages (a) and the survival index of macrophage-internalized amastigotes (b) after $48 \mathrm{~h}$ of exposure. Murine peritoneal macrophages were infected with promastigote forms of $L$. amazonensis and then treated with concentrations related to respective $\mathrm{IC}_{50}, 1 / 2 \mathrm{IC}_{50}$, and $1 / 4 \mathrm{IC}_{50}$ against promastigotes. Results represent the means \pm SEM of three experiments performed in triplicate. ${ }^{* * *} P<0.001$ versus control. 


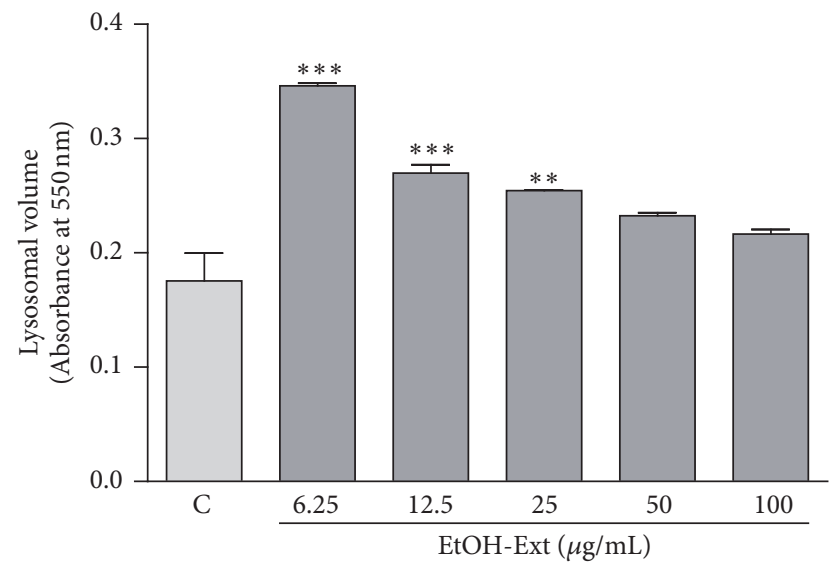

(a)

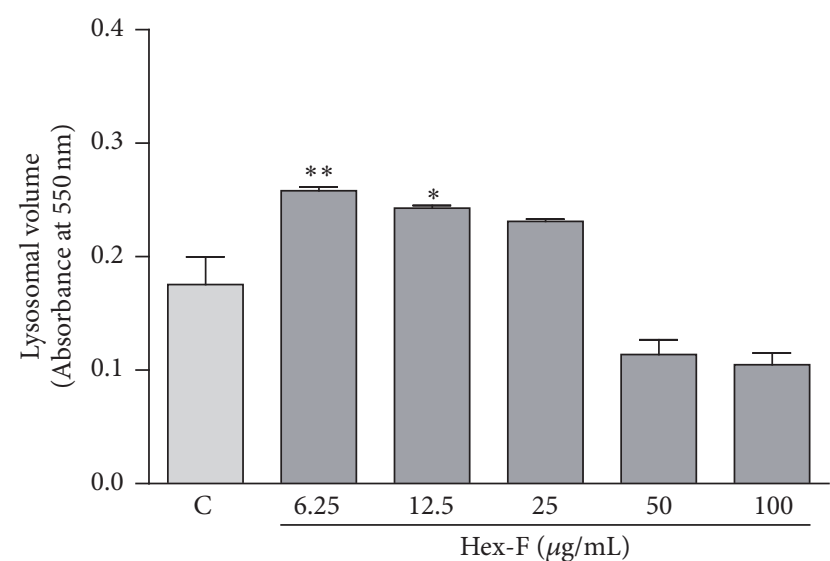

(b)

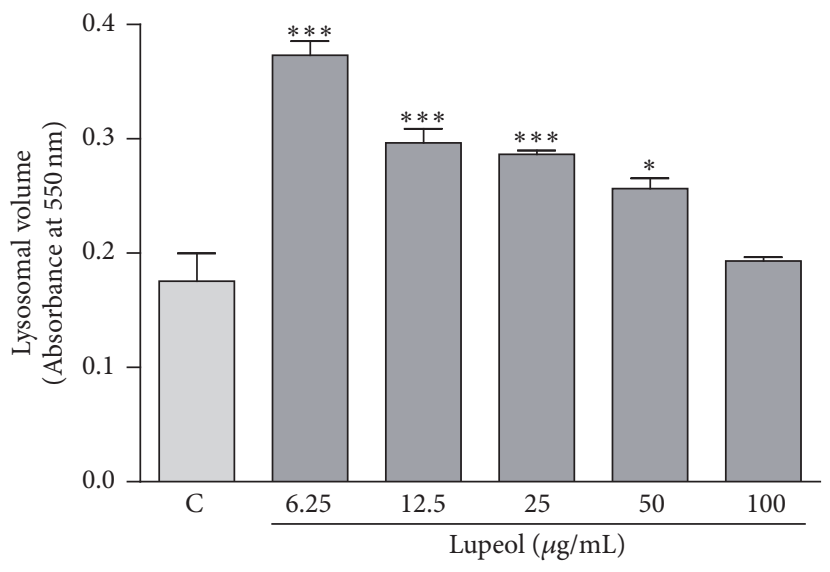

(c)

FIgURE 7: The influence of EtOH- Ext (a), Hexanic fraction (b), and Lupeol (c) on the lysosomal volume in macrophages. Murine peritoneal macrophages were incubated for $48 \mathrm{~h}$ after treatment. Lysosomal volume was analyzed spectrophotometrically by the increase in neutral red (NR) uptake following solubilization with the extraction solution. Data are presented as mean \pm SEM of three experiments carried out in triplicate. ${ }^{*} P<0.05$ versus control; ${ }^{* *} P<0.01$ versus control; ${ }^{* * *} P<0.001$ versus control.

EtOH-Ext, Hex-F, and Lupeol present SI higher than 1.0, which reveals the safety of these substances and the continuity in further studies of antileishmanial activity.

Once the EtOH-Ext, Hex-F, and the main constituent Lupeol showed effective antileishmanial activity with selective action towards the parasite, we decided to investigate their activities against the intramacrophagic amastigotes. This experimental model assesses the effects against the parasite by the activation of microbicidal mechanisms in the host macrophages and therefore is as closest as possible to the in vivo effect [33]. In these experiments, all treatments presented antileishmanial activity against the macrophageinternalized amastigotes, which was observed by the significant reduction in the number of infected macrophages and in the number of amastigotes per macrophage. Thus, these results reinforce studies concerning which mechanisms triggered in macrophages might be involved in this effect.
Activated macrophages perform several functions, including phagocytosis, increased numbers of hydrolytic enzymes from lysosomal compartments, tumor cytotoxicity, cytokine secretion, and antigen presentation. Phagocytosis and lysosomal volume are functions of innate immunity, important for the control of infections and leading to the degradation of pathogens and the presentation of antigens $[34,35]$. Thus, in order to evaluate this hypothesis, parameters related to activation of macrophages and structural mechanisms of antileishmanial activity (lysosomal compartment volume and phagocytic activity), as well as the nitrite production as a mechanism of the activation state of the macrophages, were assessed.

The incorporation of neutral red into the secretory vesicles was applied to study the lysosomal volume. Besides, the phagocytic capability was determined by the incorporation of zymosan particles stained with neutral red. Zymosan 


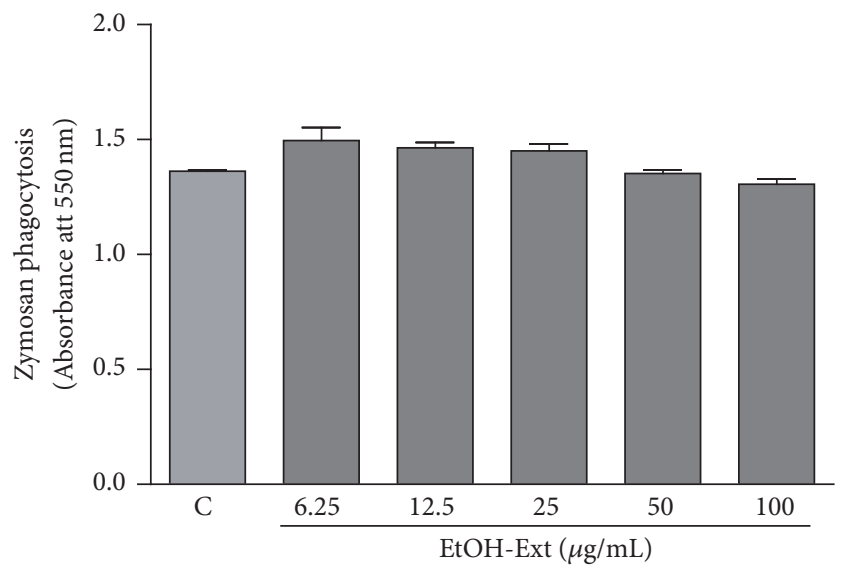

(a)

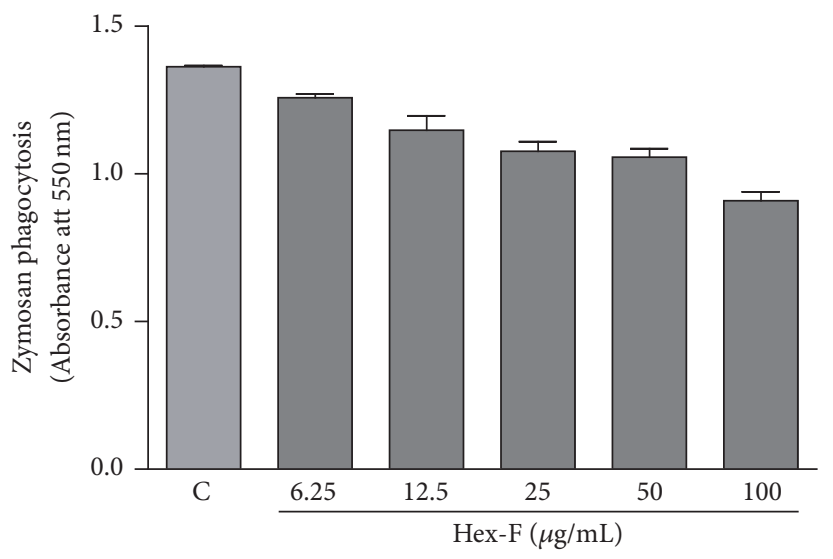

(b)

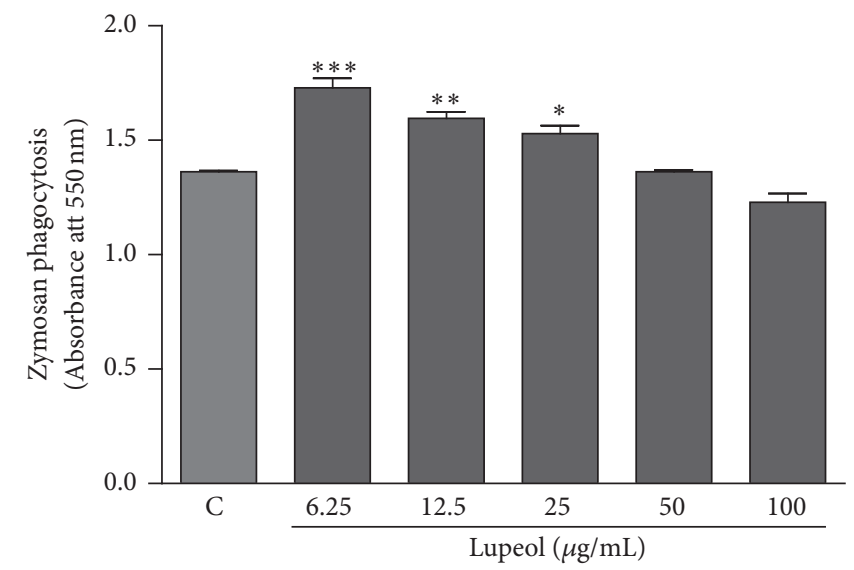

(c)

Figure 8: The influence of EtOH- Ext (a), Hexanic fraction (b), and Lupeol (c) on the phagocytosis in macrophages. Murine peritoneal macrophages were treated with a range of concentrations for $48 \mathrm{~h}$. The phagocytosis was analyzed by incorporation of NR-stained zymosan, solubilized with the extraction solution. Data are presented as mean \pm SEM of three experiments carried out in triplicate. ${ }^{*} P<0.05$ versus control; ${ }^{* *} P<0.01$ versus control; ${ }^{* * *} P<0.001$ versus control.

is a polysaccharide from the cell wall of Saccharomyces cerevisiae in the form of water-insoluble powder [36]. In this study, the antiamastigote activity of EtOH-Ext, Hex-F, and Lupeol may involve the increase of lysosomal volume, since all the treatments promoted an increase of the volume of the endocytic compartment. Interestingly, the increase of phagocytic capacity induced by Lupeol may also be related to its antiamastigote activity, considering Lupeol was the only treatment which increase the phagocytosis of zymosan particles in macrophages.

Another important pathway that may be involved in the mechanism of antileishmanial activity is stimulation of $\mathrm{NO}$ production by macrophages. This mechanism has been considered as the most effective mechanism underlying defense against Leishmania spp. infection [37]. This production can be stimulated in vitro by the activation of macrophages using lipopolysaccharide (LPS), which activates the inducible nitric oxide synthase (iNOS), then leading to the production of high concentrations of NO. However, the results showed that EtOH-Ext, Hex-F, and Lupeol lack the ability to stimulate
NO production by macrophages, indirectly determined by the nitrite measurement using Griess' Reaction. Thus, the antiamastigote effect of these treatments probably does not involve the NO pathway.

\section{Conclusion}

This study demonstrates that EtOH-Ext, Hex-F, and Lupeol obtained from $P$. insignis were able to promote effective and selective antileishmanial activity against both promastigote and amastigote forms of $L$. amazonensis, as well as against macrophage-internalized amastigote forms. This study also demonstrated the mechanisms underlying antileishmanial effect, such as the increase of lysosomal volume of macrophages for all treatments. Interestingly, only Lupeol was able to promote increase the phagocytic capacity of macrophages, suggesting this compound might be characterized as the biomarker for the antileishmanial effect of $P$. insignis stem bark. Thus, the involvement of innate immune system was evidenced. Further investigations are 


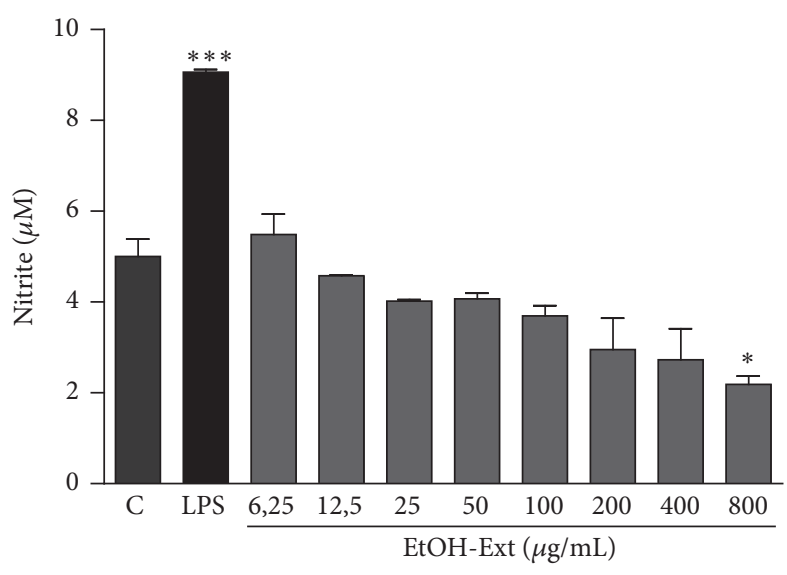

(a)

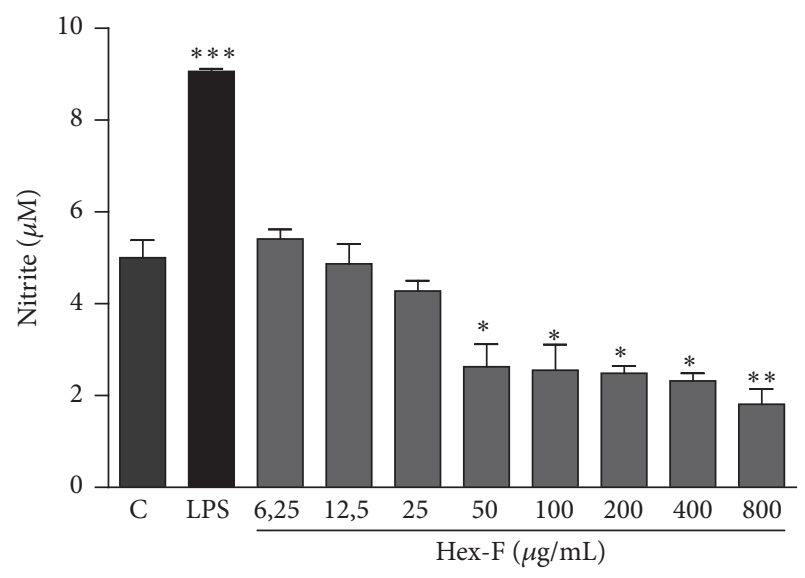

(b)

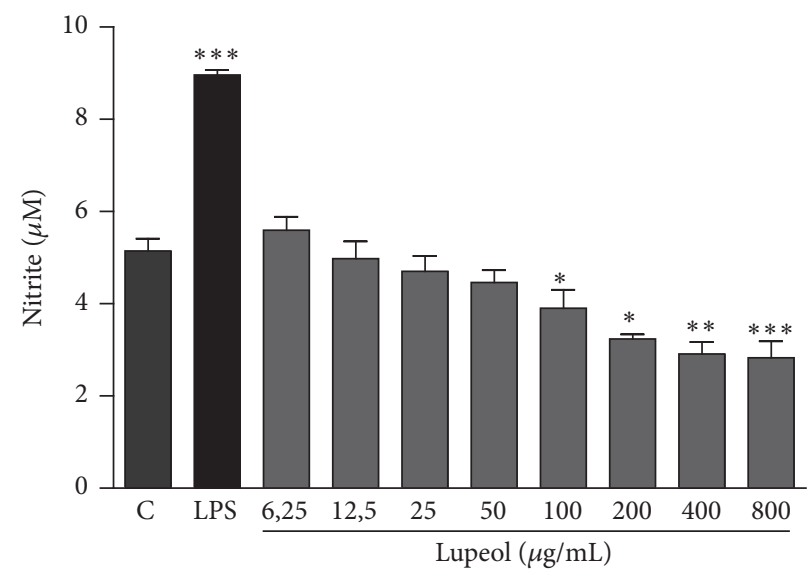

(c)

FIGURE 9: Production of nitrite in murine peritoneal macrophages treated with EtOH-Ext (a), Hex-F (b), and Lupeol (c). Murine peritoneal macrophages were treated and then incubated for $24 \mathrm{~h}$. After this period, supernatants were mixed with Griess' reagent in equal parts. LPS, bacterial lipopolysaccharide $(2 \mathrm{mg} / \mathrm{mL})$. Data are presented as mean \pm SEM of three experiments carried out in triplicate. ${ }^{*} P<0.05$ versus control; ${ }^{* *} P<0.01$ versus control; ${ }^{* * *} P<0.001$ versus control.

recommended in order to determine the potential antileishmanial effect of this species in experimental in vivo models of leishmaniasis.

\section{Conflicts of Interest}

The authors declare they have no conflicts of interest for this work.

\section{References}

[1] S. Rath, L. A. Trivelin, T. R. Imbrunito et al., "Antimoniais empregados no tratamento da leishmaniose: estado da arte," Química Nova, vol. 26, no. 4, pp. 550-555, 2003.

[2] WHO, “Leishmaniasis," 2017, http://www.who.int/mediacentre/ factsheets/fs375/en/.

[3] S. L. Croft, S. Sundar, and A. H. Fairlamb, "Drug resistance in leishmaniasis," Clinical Microbiology Reviews, vol. 19, no. 1, pp. 111-126, 2006.
[4] F. Chappuis, S. Sundar, A. Hailu et al., "Visceral leishmaniasis: what are the needs for diagnosis, treatment and control?" Nature Reviews Microbiology, vol. 5, no. 11, pp. 873-882, 2007.

[5] S. Sundar, J. Chakravarty, D. Agarwal, M. Rai, and H. W. Murray, "Single-dose liposomal amphotericin B for visceral leishmaniasis in India," New England Journal of Medicine, vol. 362, no. 6, pp. 504-512, 2010.

[6] S. Sundar, A. Singh, M. Rai, and J. Chakravarty, "Single-dose indigenous liposomal amphotericin B in the treatment of Indian visceral leishmaniasis: A phase 2 study," American Journal of Tropical Medicine and Hygiene, vol. 92, no. 3, pp. 513-517, 2015.

[7] L. A. Dutra, L. de Almeida, T. G. Passalacqua et al., "Leishmanicidal activities of novel synthetic furoxan and benzofuroxan derivatives," Antimicrobial Agents and Chemotherapy, vol. 58, no. 8, pp. 4837-4847, 2014.

[8] J. Costa, F. Rodrigues, E. Angélico et al., "Estudo químicobiológico dos óleos essenciais de Hyptis martiusii, Lippia sidoides e Syzigium aromaticum frente às larvas do Aedes aegypti," Revista Brasileira de Farmacognosia, vol. 15, no. 4, pp. 304-309, 2005. 
[9] J. G. Costa, F. F. Rodrigues, E. C. Angélico et al., "Composição química e avaliação da atividade antibacteriana e toxicidade do óleo essencial de Croton zehntneri (variedade estragol)," Revista Brasileira de Farmacognosia, vol. 18, no. 4, pp. 583-586, 2008.

[10] L. P. Aguiar, R. W. Figueiredo, R. E. Alves, G. A. Maia, and V. A. Souza, "Caracterização física e físico-química de frutos de diferentes genótipos de bacurizeiro (Platonia insignis Mart.)," Ciência e Tecnologia de Alimentos, vol. 28, no. 2, pp. 423-428, 2008.

[11] R. Q. S. Júnior, L. C. Soares, A. L. M. Filho et al., "Estudo histológico da cicatrização de feridas cutâneas utilizando a banha de bacuri (Platonia insignis Mart.)," ConScientiae Saúde, vol. 9, no. 4, 2010.

[12] S. M. P. Carneiro, F. A. A. Carvalho, L. C. L. R. Santana, A. P. L. Sousa, J. M. M. Neto, and M. H. Chaves, "The cytotoxic and antileishmanial activity of extracts and fractions of leaves and fruits of Azadirachta indica (A Juss.)," Biological Research, vol. 45, no. 2, pp. 111-116, 2012.

[13] T. Ueda-Nakamura, R. R. Mendonça-Filho, J. A. Morgado-Díaz et al., "Antileishmanial activity of Eugenol-rich essential oil from Ocimum gratissimum," Parasitology International, vol. 55, no. 2, pp. 99-105, 2006.

[14] S. Al-Nasiry, M. Hanssens, C. Luyten, and R. Pijnenborg, "The use of Alamar Blue assay for quantitative analysis of viability, migration and invasion of choriocarcinoma cells," Human Reproduction, vol. 22, no. 5, pp. 1304-1309, 2007.

[15] K. A. D. F. Rodrigues, L. V. Amorim, J. M. G. D. Oliveira et al., "Eugenia uniflora L. essential oil as a potential antileishmania agent: effects on leishmania amazonensis and possible mechanisms of action," Evidence-based Complementary and Alternative Medicine, vol. 2013, Article ID 279726, 2013.

[16] S. J. R. Bonatto, A. Folador, J. Aikawa et al., "Lifelong exposure to dietary fish oil alters macrophage responses in walker 256 tumor-bearing rats," Cellular Immunology, vol. 231, no. 1-2, pp. 56-62, 2004.

[17] F. C. C. Grando, C. A. Felício, A. Twardowschy et al., "Modulation of peritoneal macrophage activity by the saturation state of the fatty acid moiety of phosphatidylcholine," Brazilian Journal of Medical and Biological Research, vol. 42, no. 7, pp. 599-605, 2009.

[18] D. C. Soares, C. G. Pereira, M. Â. A. Meireles, and E. M. Saraiva, "Leishmanicidal activity of a supercritical fluid fraction obtained from Tabernaemontana catharinensis," Parasitology International, vol. 56, no. 2, pp. 135-139, 2007.

[19] S. B. Mahato and A. P. Kundu, " ${ }^{13}$ C NMR Spectra of pentacyclic triterpenoids-a compilation and some salient features," Phytochemistry, vol. 37, no. 6, pp. 1517-1575, 1994.

[20] V. F. Veiga Jr., A. C. Pinto, and M. A. M. Maciel, "Medicinal plants: safe cure?” Quimica Nova, vol. 28, no. 3, pp. 519-528, 2005.

[21] K. K. L. Yamaguchi, C. Victor, L. Pereira, E. S. Lima, and V. Florêncio, "Química e farmacologia do bacuri (Platonia insignis)," Scientia Amazonia, pp. 39-46, 2014.

[22] Z. Ovesná, A. Vachálková, K. Horváthová, and D. Tóthová, "Pentacyclic triterpenoic acids: new chemoprotective compounds. Minireview," Neoplasma, vol. 51, no. 5, pp. 327-333, 2004.

[23] I. Murtaza, M. Saleem, V. M. Adhami, B. B. Hafeez, and H. Mukhtar, "Suppression of cFLIP by lupeol, a dietary triterpene, is sufficient to overcome resistance to TRAIL-mediated apoptosis in chemoresistant human pancreatic cancer cells," Cancer Research, vol. 69, no. 3, pp. 1156-1165, 2009.
[24] L. Fumarola, R. Spinelli, and O. Brandonisio, "In vitro assays for evaluation of drug activity against Leishmania spp.," Research in Microbiology, vol. 155, no. 4, pp. 224-230, 2004.

[25] J. S. C. Júnior, A. A. C. De Almeida, A. De Barros Falcão Ferraz et al., "Cytotoxic and leishmanicidal properties of garcinielliptone FC, a prenylated benzophenone from platonia insignis," Natural Product Research, vol. 27, no. 4-5, pp. 470-474, 2013.

[26] R. Di Pasqua, G. Betts, N. Hoskins, M. Edwards, D. Ercolini, and G. Mauriello, "Membrane toxicity of antimicrobial compounds from essential oils," Journal of Agricultural and Food Chemistry, vol. 55, no. 12, pp. 4863-4870, 2007.

[27] A. Ultee, E. P. W. Kets, M. Alberda, F. A. Hoekstra, and E. J. Smid, "Adaptation of the food-borne pathogen Bacillus cereus to carvacrol," Archives of Microbiology, vol. 174, no. 4, pp. 233238, 2000.

[28] A. C. Fortes, A. A. C. Almeida, F. J. B. Mendonça-Júnior, R. M. Freitas, J. L. Soares-Sobrinho, and M. F. De La Roca Soares, "Anxiolytic properties of new chemical entity, 5TIO1," Neurochemical Research, vol. 38, no. 4, pp. 726-731, 2013.

[29] M. C. De Almeida, V. Vilhena, A. Barral, and M. Barral-Netto, "Leishmanial infection: analysis of its first steps. A review," Memorias do Instituto Oswaldo Cruz, vol. 98, no. 7, pp. 861-870, 2003.

[30] J. S. Armstrong, "Mitochondrial membrane permeabilization: the sine qua non for cell death," BioEssays, vol. 28, no. 3, pp. 253-260, 2006.

[31] S. Kamhawi, "Phlebotomine sand flies and Leishmania parasites: friends or foes?" Trends in Parasitology, vol. 22, no. 9, pp. 439-445, 2006.

[32] J. D. Berman, "Human leishmaniasis: clinical, diagnostic, and chemotherapeutic developments in the last 10 years," Clinical Infectious Diseases, vol. 24, no. 4, pp. 684-703, 1997.

[33] F. K. A. Rodrigues, C. N. de, S. Dias et al., "2-Amino-thiophene derivatives present antileishmanial activity mediated by apoptosis and immunomodulation in vitro," European Journal of Medicinal Chemistry, vol. 106, pp. 1-14, 2015.

[34] W. L. Lee, R. E. Harrison, and S. Grinstein, "Phagocytosis by neutrophils," Microbes and Infection, vol. 5, no. 14, pp. 1299$1306,2003$.

[35] F. Niedergang and P. Chavrier, "Signaling and membrane dynamics during phagocytosis: many roads lead to the phagos(R)ome," Current Opinion in Cell Biology, vol. 16, no. 4, pp. 422-428, 2004.

[36] W.-C. Wei, Y.-H. Su, S.-S. Chen, J.-H. Sheu, and N.-S. Yang, "GM-CSF plays a key role in zymosan-stimulated human dendritic cells for activation of Th1 and Th17 cells," Cytokine, vol. 55, no. 1, pp. 79-89, 2011.

[37] K. R. Gantt, T. L. Goldman, M. L. McCormick et al., "Oxidative responses of human and murine macrophages during phagocytosis of leishmania chagasi," The Journal of Immunology, vol. 167, no. 2, pp. 893-901, 2001. 


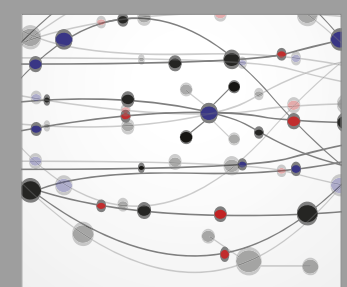

The Scientific World Journal
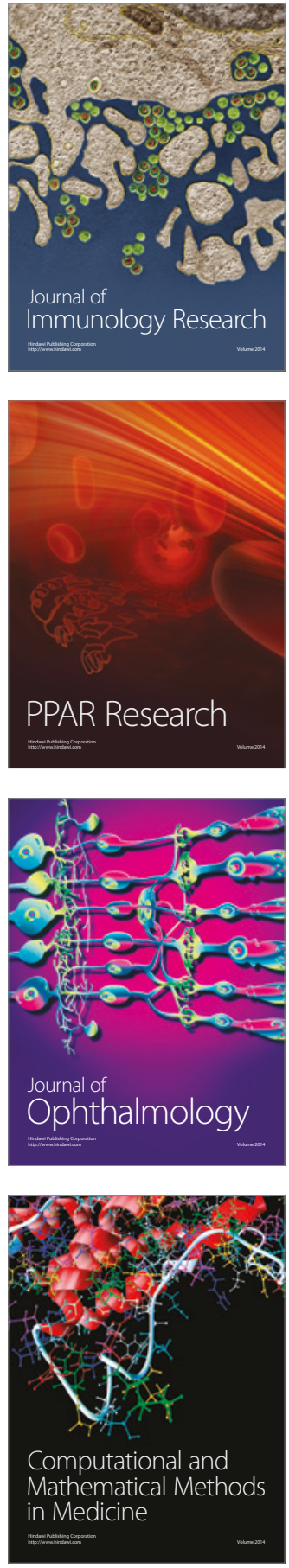

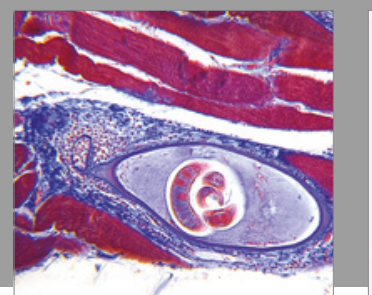

Gastroenterology Research and Practice
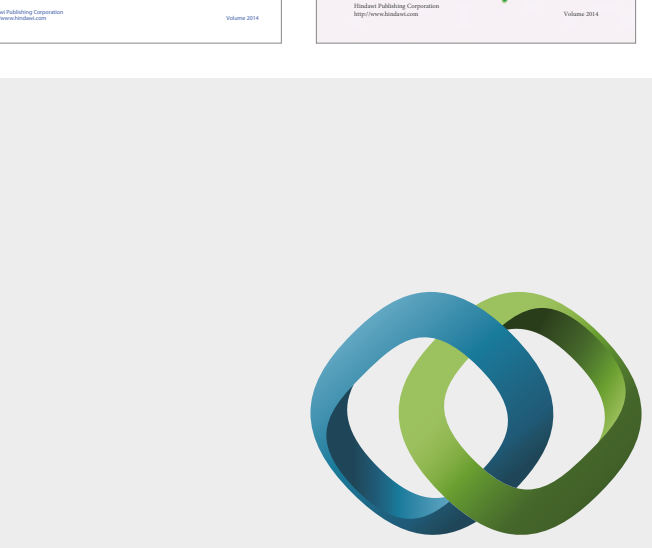

\section{Hindawi}

Submit your manuscripts at

https://www.hindawi.com
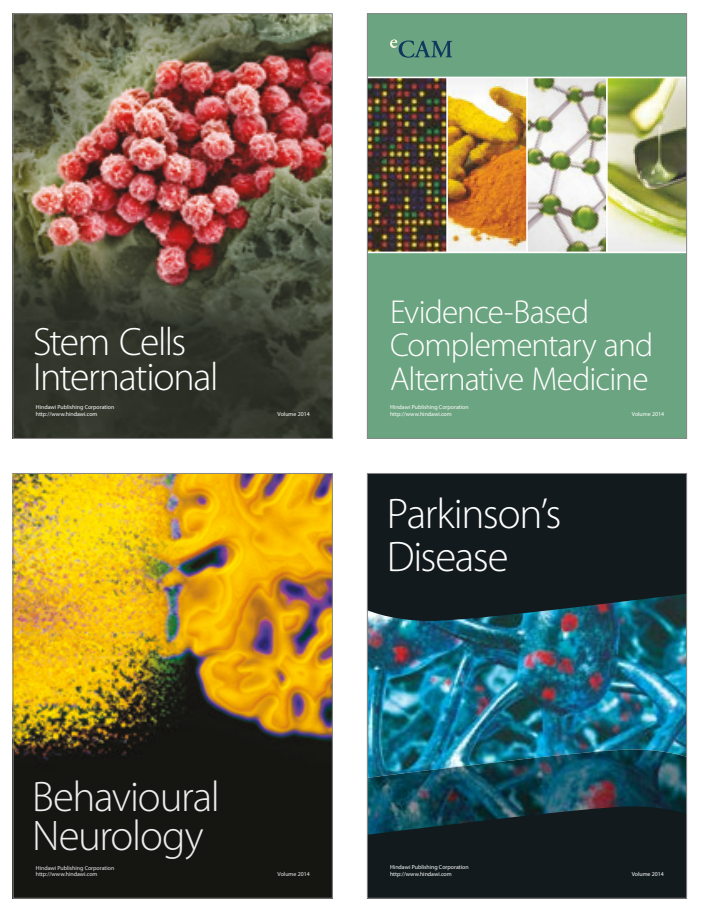
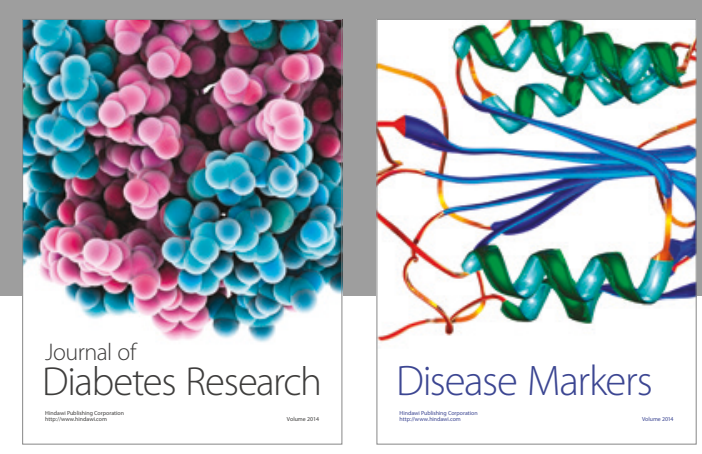

Disease Markers
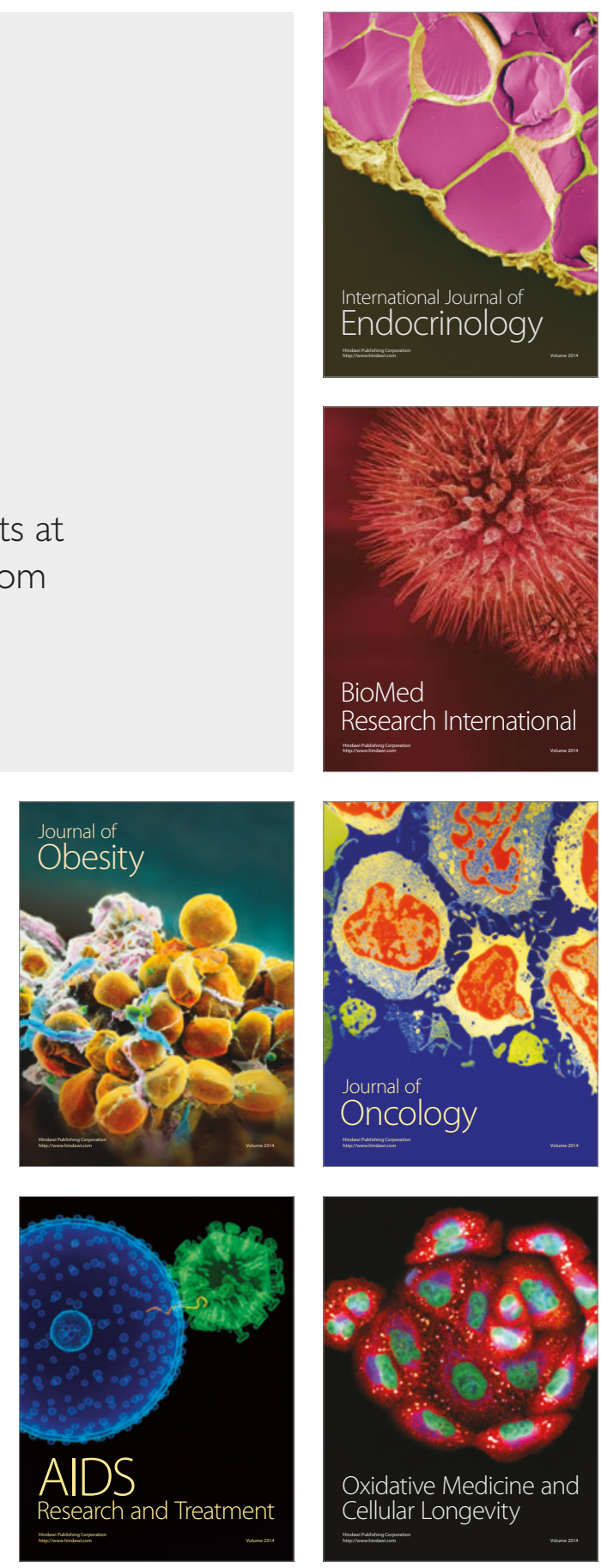